\title{
Abdominal Stretching as a Therapy for Dysmenorrhea
}

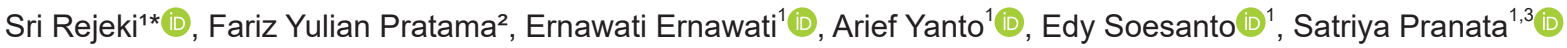 \\ ${ }^{1}$ Department of Nursing, Faculty of Nursing, Universitas Muhammadiyah Semarang, Semarang, Indonesia; ${ }^{2}$ Department of \\ Nursing, Nurse Advisor and Practitioner Nursing Laboratory, Universitas Muhammadiyah Semarang, Semarang, Indonesia; \\ ${ }^{3}$ Department of Nursing, School of Nursing, National Taipei University of Nursing and Health Sciences, Taipei, Taiwan
}

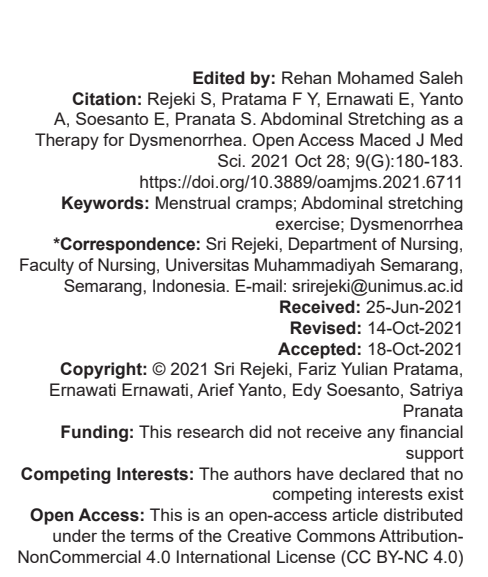

Abstract

BACKGROUND: Dysmenorrhea is pain during the menstrual period caused by uterine muscle cramps. The Dysmenorrhea prevalence in Indonesia is categorized as high at $64.25 \%$. The dysmenorrhea symptom could be very disruptive and even decrease women's productivity. Related to this problem, abdominal stretching is one of the alternatives to reduce pain from dysmenorrhea.

AIM: This research was aimed to find out the effect of abdominal stretching on the pain intensity of menstrual cramps. METHODS: It was a quasi-experimental research with a pre-test post-test control group design. The sample was 130 female adolescents that were taken by total sampling. The sample was divided into two groups, which were the intervention group and the control group.

RESULTS: The research finding, with a $0.000(p<0.005)$ significance value was obtained by using the Wilcoxon test CONCLUSION: It means abdominal stretching exercise is significantly effective to reduce pain intensity from menstrual cramps (dysmenorrhea) in female adolescents. It is suggested to implement abdominal stretching as nursing care for menstrual cramps.

\section{Introduction}

Menstruation is periodical and cyclical uterine bleeding accompanied by endometrium desquamation which is also a sign that a woman is in her puberty period [1]. A woman first gets her period between 12 and 15 years old, depends on some factors such as health, nutrition status, and weight [2], [3]. Menstruation is a normal physiological process and event in female adolescents [4]. However, some of them might have a problem during their period. The most complained gynecological problem during menstruation may vary from the irregular menstrual cycle, menorrhagia, dysmenorrhea, and other related symptoms. Dysmenorrhea is mainly related to the previous ovulation with uterine muscle contraction and the prostaglandin secretion which leads to uterine muscle cramps [1], [5].

Dysmenorrhea is categorized into two, (1) primary dysmenorrhea related to the menstrual cramps without any genital anatomy abnormality; (2) secondary dysmenorrhea is menstrual cramps with a particular anatomic disorder or any pelvic pathology problem [6]. Dysmenorrhea prevalence in Indonesia is about 64.25\% which consists of $54.89 \%$ primary dysmenorrhea and $9.36 \%$ secondary dysmenorrhea [6]. Primary dysmenorrhea commonly happens 1-2 years after the menarche [3], [6]. Meanwhile, the common menarche age for Indonesian adolescents is 13-14 years old [7]. Based on the data, the dysmenorrhea experienced by female adolescents between 16 and 18 years old, or when they are in high school years [1]

Primary dysmenorrhea and other systemic symptoms are mainly caused by the high level of prostaglandin. After the ovulation, as the response to progesterone production, the fatty acid in the Phospholipid cell membrane is increased. Then, arachidonic acid is released and starts the prostaglandin cascade in the uterus. Prostaglandin (PGF-2 $\alpha$ ) turns to hypertonic myometrium and vasoconstriction which leads to ischemia and pain [1].

The bad treatment of dysmenorrhea could cause female activity disruption. The activity disruption could happen in women, especially the active and dynamic adolescents in their growth and developmental period. The severe pain during menstruation leads to activity intolerance, such as absence from work or school. It decreases work output and affects learning achievement [8]. For example, a female high school student who suffers from dysmenorrhea could not fully concentrate on her study and unfortunately must be 
absent from school [4]. A study reports that primary dysmenorrhea is proven to affect women's life quality at $40-90 \%$, where one out of 13 women with primary dysmenorrhea is absent from work or school for 1-3 days every month [2], [4], [8].

According to the International Association for the study of Pain, pain is the main reason for someone to seek healthcare [9]. Someone with pain also feels the stress and torture, so that he or she is driven to find relief. Pain is the source of frustration either for patients or health workers [10]. For some adolescents, primary dysmenorrhea is particular torture they have to suffer every month [2]. It drives them to find the perfect solution for the problem. There are some solutions to relieve pain from menstrual cramps, either pharmacological therapy or non-pharmacological therapy [1]. Nonpharmacological pain management is considered to be safer than pharmacological therapy as it may have a side effect [11].

Pharmacology therapy usually uses painrelief medicine including analgesic (painkiller) from non-steroid anti-inflammation drugs categories, such as paracetamol or acetaminophen (sumagesic, panadol, etc.), mefenamic acid (ponstelax, nichostan, etc), ibuprofen (ribunal, ostarin, etc.), metamizole or methampyron (pyronal, novalgin, etc.), and other painrelief medicine [12]. Non-pharmacological therapy could vary from warm compress, warm shower, massage, exercise, enough sleep, hypnotherapy, distraction such as listening to music, and relaxation in the form of yoga and deep breathing technique [10]. Several studies found that exercise could deal with dysmenorrhea [13]. Moreover, exercise is safer as it does no't have any side effects which may distract the physiological process of the body [6], [13]. Physical exercise could trigger endorphin, the natural opiate from the human body to increase the feeling of well-being and reduce pain [9]. The increasing endorphin level in the body could reduce pain from the contraction. Exercise is proven to increase endorphin in the blood 4-5 times higher. Therefore, the more exercise we do, the higher the endorphin level in our blood [13].

Abdominal stretching exercise is an exercise to reduce menstrual pain (dysmenorrhea). Abdominal stretching exercise is a physical exercise that includes abdominal muscle stretching for 10-15 min to improve muscle strength, endurance, and flexibility [13]. It is expected to be able in reducing pain from menstrual cramps in female adolescents. It is also supported by study that exercise is effective to decrease pain from dysmenorrhea [2], [13], [14].

Based on the preliminary study done by the researcher in October 2017 in Senior High School 3 Brebes, 192 out of all female ten grade students in Senior High School 3 Brebes had dysmenorrhea experience. Female students with dysmenorrhea tend to have study distraction, as the pain requires them to be absent from school and affect their learning concentration. From the phenomena above, the researcher is interested to conduct action research with non-pharmacological pain management by using abdominal stretching exercises.

\section{Methodology}

It was a quasi-experimental study with a pre-test and post-test control group design. 130 female students were taken as a sample by using total sampling. The sample was then divided into two groups using simple random sampling with 65 respondents as the control group and 65 respondents as the intervention group. Both groups were given pre-test and post-test.

In this research design, the pain intensity before and after the treatment of the intervention group was measured. It was measured using the Numeric Rating Scale. The pain intensity observation result of the intervention group was then compared with the observation result of the control group.

\section{Finding}

Based on Table 1, it could be seen that the respondents are mostly 16 years old with a minimum age at 15 and maximum age at 17 .

Table 1: Respondent distribution based on age

\begin{tabular}{llllll}
\hline Variable & $\mathrm{n}$ & Min & Max & Mean & Deviation Std. \\
\hline Age & 130 & 15 & 17 & 16 & 0.431 \\
\hline
\end{tabular}

The Pain intensity before and after the abdominal stretching exercise treatment In intervention group.

Based on Table 2 it was found that dysmenorrhea pain intensity experienced by female adolescents before the abdominal stretching exercises was 4.58 with a minimum score at 2 and a maximum score at 8 . meanwhile, after the abdominal stretching exercise, it was found that the mean of the pain intensity was 1.46 with the minimum score at 0 and maximum score at 4.

Table 2: The distribution of the dysmenorrhea pain intensity mean before and after the abdominal stretching treatment

\begin{tabular}{lllll}
\hline Variable & $\mathrm{n}$ & Min & Max & Mean \\
\hline Pain Intensity before the Abdominal Stretching Exercise & 65 & 2 & 8 & 4.58 \\
Pain Intensity after the Abdominal Stretching Exercise & 65 & 0 & 4 & 1.46 \\
& 65 & & & \\
\hline
\end{tabular}

The dysmenorrhea pain intensity before and after in control group

Table 3: The distribution of dysmenorrhea pain intensity mean in the control group

\begin{tabular}{lllll}
\hline Variable & $\mathrm{n}$ & Min & Max & Mean \\
\hline Pain Intensity before in control group & 65 & 2 & 8 & 4.48 \\
Pain Intensity before in control group & 65 & 1 & 7 & 3.47 \\
& 65 & & & \\
\hline
\end{tabular}


Based on Table 3 it was found that the pain intensity experienced by the control group was 4.48 with a minimum score of 2 and a maximum score of 8 .

The effect of abdominal stretching toward dysmenorrhea pain intensity.

Based on Table 4, the finding of bivariate analysis using the Wilcoxon test was $p<0.05(0.000)$. it means that there is a significant difference between pain intensity before and after the abdominal stretching exercise for female adolescents in Senior High School 3 Brebes.

Table 4: wilcoxon test result in intervention and control group

\begin{tabular}{llll}
\hline Variable & $\mathrm{n}$ & Mean & Sig. \\
\hline Pain intensity before & 130 & 65.84 & 0.000 \\
Pain intensity after & & 22.00 & \\
\hline
\end{tabular}

\section{Discussion}

Based on the research finding, the mean of dysmenorrhea pain intensity before the implementation of the abdominal stretching exercise was 4.58 with a maximum score of 8 which shows severe or intolerable pain. Dysmenorrhea caused by uterine muscle cramps starts $24 \mathrm{~h}$ before menstruation and can last for 24-36 h. However, it usually happens in the first $24 \mathrm{~h}$ after the bleeding. Dysmenorrhea is a normal condition for women or female adolescents during their menstruation. However, the pain might be unbearable. The bad treatment of dysmenorrhea could disrupt daily activity as women may feel weak, stress, depressed, collection of menstrual blood in the pelvis, severe cramps accompanied by secretion of menstrual clots from the uterus, pelvic cavity problem which may lead to severe uterine contraction [3], [6], [8].

Dysmenorrhea is affected by physical and psychological factors, such as stress and a high level of prostaglandins [6]. The excessive prostaglandin release will be diffused into endometrial tissue which leads to the amplitude and frequency of uterine contraction. It may also cause uterine ischemia, uterine tissue hypoxia, endometrium disintegration, bleeding, and low abdominal cramps [1]. Abdominal stretching to reduce dysmenorrhea pain intensity [14].

In this research, it was found that some respondents experienced level 8 pain. it means severe and unbearable menstrual pain which makes the respondents unable to do their normal activity either at work or school. The Intolerable pain in respondents is caused by the excessive production of adrenaline, estrogen, progesterone, and prostaglandins hormones. estrogens could improve excessive uterine contraction, meanwhile, progesterone halts the contraction. excessive contraction may lead to pain. Besides, the increase of adrenaline could stiffen body muscle, including uterine muscle which is painful during menstruation [1], [4], [6], [9].

Based on this study, Table 4 shows the pain intensity after the implementation of abdominal stretching is at 1.46 with the mean of pain intensity before the implementation of the treatment was 4.58. the mean pain intensity of the control group is 4.48. Therefore, It could be concluded that there is a significant effect of abdominal stretching to reduce pain intensity in female adolescents with dysmenorrhea.

Exercise is one of the non-pharmacological pain management which is considered to be safe, as it only employs physiology [13], [14]. The significance of exercise habits toward dysmenorrhea in which the psychologist and physical symptoms of primary dysmenorrhea are decreased. Regular exercise triggers the secretion of endorphins. the more exercises, the higher level of endorphins released. endorphins are formed in the brain and the spinal nervous system. the released endorphins are then caught by the receptor in the hypothalamus and limbic system to manage emotion. this hormone acts as a natural sedative to give a sense of comfort and reduce pain [9], [12], [13], [14]

Therefore, one of the exercises to reduce menstrual pain is abdominal stretching exercise. the implementation of abdominal stretching exercise during menstruation could improve muscle strength, endurance, muscle flexibility, pain relief, and reduce contraction to reduce menstrual pain (dysmenorrhea) [14]. The aim of the muscle stretching muscle is to improve oxygenation (the cellular process of transferring oxygen and carbohydrate) and stimulate the drainage flow of the lymph, as a result, it could increase muscle flexibility and maintain the function well, while fix the elasticity and flexibility of the body tissue to reduce muscle cramps [1], [14].

It is in line with gate control theory which explains about pain impulse is transmitted when the defense is opened and halted when the defense is closed. the effort to close the defense is a basis for pain relief therapy [9]. The blockage could be done using relaxation techniques to distract our attention. abdominal stretching is one of the relaxation techniques to reduce pain by relaxing spasm muscle contributed by the increase of prostaglandins level. it can cause vasodilation of blood vessels and increase blood flow to the spasm and ischemic area.

\section{Conclusion}

The mean of dysmenorrhea intensity in female adolescents before the implementation of abdominal stretching was 4.58 and was reduced to 1.46 after the implementation of abdominal stretching. The 
reduction of dysmenorrhea pain intensity mean after the implementation of abdominal stretching was a minimum of 0 and a maximum of 2 . There is a significant effect of abdominal stretching toward dysmenorrhea pain intensity in female adolescents as Wilcoxon test result showed $p=0.000$. This information can be used to handle female adolescents with dysmenorrhea by using a non-pharmacological technique.

\section{References}

1. Rejeki S, Solichan A, MacHmudah, Safitri DN, Poddar S. The profile of interleukin-6, PGE2, and menstrual pain levels through the counter pressure regiosacralis therapy. Eur J Mol Clin Med. 2020;7(6):122-8.

2. Kemigisha E, Rai M, Mlahagwa W, Nyakato VN, Ivanova $\mathrm{O}$. A qualitative study exploring menstruation experiences and practices among adolescent girls living in the nakivale refugee settlement, Uganda. Int J Environ Res Public Health. 2020;17(18):1-11. https://doi.org/10.3390/ijerph17186613 PMid:32932817

3. Critchley HO, Babayev E, Bulun SE, Clark S, Garcia-Grau I, Gregersen PK, et al. Menstruation: Science and society. Am J Obstet Gynecol. 2020;223(5):624-64. https://doi.org/10.1016/j. ajog.2020.06.004

PMid:32707266

4. Abreu-Sánchez A, Parra-Fernández ML, Onieva-Zafra MD, Fernández-Martínez E. Perception of menstrual normality and abnormality in spanish female nursing students. Int J Environ Res Public Health. 2020;17(17):1-12. https://doi.org/10.3390/ ijerph17176432

PMid:32899383

5. Prajapati J, Patel R. Menstrual hygiene among adolescent girls: A cross sectional study in urban community of Gandhinagar.
J Med Res. 2015;1(4):122-5.

6. Proctor $\mathrm{M}$, Farquhar $\mathrm{C}$. Diagnosis and management of dysmenorrhoea. BMJ. 2006;332(7550):1134-8. https://doi. org/10.1136/bmj.332.7550.1134

PMid:16690671

7. Batubara JR, Soesanti F, van de Waal HD. Age at menarche in indonesian girls: A national survey. Acta Med Indones. 2010;42(2):78-81.

8. Bernardi M, Lazzeri L, Perelli F, Reis FM, Petraglia F. Dysmenorrhea and related disorders. F1000Res. 2017;6:1645. https://doi.org/10.12688/f1000research.11682.1

PMid:28944048

9. Treede RD. The international association for the study of pain definition of pain: As valid in 2018 as in 1979, but in need of regularly updated footnotes. Pain Rep. 2018;3(2):e643-3. https://doi.org/10.1097/pr9.0000000000000643 PMid:29756089

10. Smeltzer SC, Bare BG, Hinkle JL, Cheever Kerry H, Garret TM. Brunner and Suddarth's Text Book of Medical Surgical Nursing. Netherlands: Wolters Kluwer India Pvt. Ltd.; 2010. p. 151-7.

11. Pranata $\mathrm{S}, \mathrm{Hs} \mathrm{KH}$, Sujianto $\mathrm{U}$. The effect of transcutaneous electrical nerve stimulation (Tens) towards pain level of patients with diabetes mellitus $(\mathrm{Dm})$ with peripheral neuropathy in diabetic foot ulcer treatment in Yogyakarta general hospital Indonesia. IOSR J Nurs Health Sci. 2016;5(5):76-80. https://doi. org/10.9790/1684-0505037680

12. Phillips WJ, Currier BL. Analgesic pharmacology: II. Specific analgesics. J Am Acad Orthop Surg. 2004;12(4):221-33. PMid: 15473674

13. Dehnavi ZM, Jafarnejad F, Kamali Z. The Effect of aerobic exercise on primary dysmenorrhea: A clinical trial study. J Educ Health Promot. 2018;7:3. https://doi.org/10.4103/jehp. jehp_79_17 PMid:29417063

14. Nadjib Bustan M, Seweng A, Ernawati E. Abdominal stretching exercise in decreasing pain of dysmenorrhea among nursing students. J Phys Conf Ser. 2018;1028(1):012103. https://doi. org/10.1088/1742-6596/1028/1/012103 